\title{
Pregnancy complications among nulliparous and multiparous women with advanced maternal age: a community- based prospective cohort study in China
}

\author{
Jiayou Luo ${ }^{1,2 \dagger}$, Chunli Fan ${ }^{3+}$, Miyang Luo ${ }^{1,2^{*}}$ (D), Junqun Fang ${ }^{4}$, Shujin Zhou ${ }^{5}$ and Fenfang Zhang ${ }^{5}$
}

\begin{abstract}
Background: This study aimed to evaluate the incidence rates and risks of pregnancy complications among nulliparous and multiparous women with advanced maternal age (AMA, $\geq 35$ years) in China.

Methods: We performed a community-based prospective cohort study of 10,171 pregnant women in selected two sub-districts and 11 towns of Liuyang from 2013 to 2015. All subjects were followed up from the first prenatal care (at $\leq 12$ weeks) to delivery, and risks of pregnancy complications were compared by parity and maternal age groups.

Results: Among nulliparas, women with AMA showed significantly increased risks for gestational hypertension (OR 8.44, 95\%Cl 1.68-2.88), preeclampsia/eclampsia (OR 9.92, 95\%Cl 4.87-18.78), premature rupture of membrane (OR 6.84, $95 \% \mathrm{Cl}$ 2.00-17.69), as compared to women in the 20-29-year age group. Among multiparas with AMA, increased risks were found for gestational diabetes mellitus (OR 3.29, 95\%Cl 1.76-5.94), anemia (OR 1.85, 95\%Cl 1.25-2.69), polyhydramnios (OR 3.29,95\% Cl 1.56-6.64), premature rupture of membrane (OR 5.14,95\% Cl 2.12-12.29), and preterm labor (OR 1.89, 95Cl 1.42-2.50).

Conclusions: Women with AMA were associated with increased risks of pregnancy complications, and complications with increased risks differed in nulliparas and multiparas. Women with AMA should be identified as a high-risk group in clinical practice.
\end{abstract}

Keywords: Community-based prospective cohort, Advanced maternal age, Pregnancy complications, Incidence

\section{Background}

Since the 1970s, the Chinese government has implemented the one-child policy to control the rapid growth of the population for around 40 years. With emerging problem of the aging population, the population policy has gradually switched to the two-child policy which encourages the birth

\footnotetext{
* Correspondence: Imy4300@gmail.com

†Jiayou Luo and Chunli Fan contributed equally to this work.

'Department of Women and Children Health, School of Public Health, Central South University, Changsha, Hunan Province, China

${ }^{2}$ Hunan Provincial Key Laboratory of Clinical Epidemiology, Changsha, Hunan Province, China

Full list of author information is available at the end of the article
}

of a second child since 2011 and has been fully implemented since 2016 [1]. With the impact of this new population policy, China is expected to see a sharp increase in fertility rate, and the proportion of women with advanced maternal age (AMA) is estimated to increase significantly [2]. Women with AMA may have increased risk for complications during pregnancy due to decreased ovarian and uterine function, as well as other concomitant diseases, which may result in threats to maternal and child health [3]. Thus, the prevention and control of complications in women with AMA during pregnancy have become a major challenge in clinical practice. 
Previous studies have reported that women with AMA had higher incidences of pregnancy complications, such as hypertensive disorders of pregnancy, gestational hypertension, placental disorders, preterm labor, maternal near miss, and maternal death [4-7]. Moreover, research also suggested that the elevated risks of pregnancy complications in AMA may differ by parity [8], and inconsistent results were reported regarding certain complications [911]. For instance, some studies found that the risk of gestational diabetes and hypertensive disorders of pregnancy were increased in both nulliparous and multiparous women with AMA [9], while in some studies the increased risks for the two complications were not observed in both nulliparas and multiparas $[10,12]$. It is therefore important to examine the association between AMA and pregnancy complications by parity within different populations and consider various confounding factors, such as disease history and lifestyle factors.

To our knowledge, only a few studies analyzed pregnancy complications and AMA in China previously, and these studies had certain limitations. The majority of previous studies were case-control or cross-sectional studies, and most studies did not conduct stratified analysis by parity $[13,14]$. Although there were two retrospective cohort studies that analyzed pregnancy complications and AMA in China $[15,16]$, these two studies only recruited patients with pregnancy complications in hospitals, thus incidence rates of different pregnancy complications among different age groups were unknown. Also, previous studies mainly focused on the population lived in urban areas, while few studies focused on women lived in rural areas. These women usually have a low educational level and low socioeconomic status, who may need more support from the healthcare system on health education and prenatal care [17].

Our study aimed to evaluate the incidence rates and risks of pregnancy complications among women with different parity and maternal age groups through a community-based prospective cohort study. This study may highlight the need for prevention of pregnancy complications among women with AMA in rural areas.

\section{Methods}

\section{Study population}

Subjects for this study were recruited from multiple maternal and child healthcare centers in Liuyang city, Hunan Province, China from June 2013 to December 2015 [18]. Liuyang is a county-level city located in the central-south region of China. It has four sub-districts and 33 towns under its jurisdiction. In this study, we randomly selected two sub-districts and 11 towns in Liuyang city to represent the population from both urban and rural areas, and the recruitment was conducted in the maternal and child healthcare centers located in each selected sub-district/ town.

Pregnant women were recruited by their gynecologists during their regular prenatal care visits with the following inclusion criteria: a) received the first prenatal care at the recruited healthcare center; b) had no more than 12 weeks of gestation. Subjects were excluded if they a) had pregnancy complications before recruitment in the first trimester of the index pregnancy because it's unclear whether the disease was started from this pregnancy or before this pregnancy; b) had an induced abortion during follow-up or did not have complete medical records from enrollment through delivery; c) had language communication barriers or were deaf; or d) refused to actively cooperate for this research.

Informed written consent was obtained from all participants. Ethical approval was obtained from the Ethics Committee of Xiangya School of Public Health, Central South University, and all research was performed in accordance with relevant guidelines/regulations.

\section{Follow-up and data collection}

Baseline information was collected for all subjects by trained research gynecologists through a face-to-face interview. The questionnaire included sociodemographic characteristics (i.e. age, education, occupation, family income, residential area), pre-pregnancy weight and height, and history of gravidity, parity, and abortion. Routine obstetric examinations and laboratory examinations were also conducted afterward. Subjects were followed up at 16 weeks, 24 weeks, 28 weeks, 32 weeks, 38 weeks of pregnancy (or before delivery), and the end of delivery, and routine obstetric examinations were conducted at each follow-up. During the follow-up period, medical records including the records of routine obstetric care, the diagnosis of pregnancy complications, and the time of diagnosis were collected. A supervisory team was assigned to check whether the follow-up was on time, verify the registered complications, and check and rearrange the missing diagnosis.

\section{Variable definitions}

Subjects were categorized into four maternal age groups, including $20-25$ years, $25-29$ years, 30-34 years, and $\geq$ 35 years. Women with AMA were defined as age greater or equal to 35 years old. Subjects aged below 20 years old were excluded in stratified analysis, due to small sample size $(n=101)$. Residential area was categorized into urban and rural residence. Family per capita annual income was classified into four categories (in Chinese Yuan, CNY): $\leq 10,000,10,001-20,000,20,001-30,000$, and $\geq 30,001$. Education levels were classified into two categories: junior high school or lower and high school/ 
college. Occupations included farmer, housewife, factory worker, and others.

Pre-pregnancy body mass index (BMI) was calculated using the formula weight $(\mathrm{kg}) /$ height $(\mathrm{m})^{2}$. BMI was categorized into three categories using Asian-specific cutoffs [19]: $<18.5 \mathrm{~kg} / \mathrm{m}^{2}, 18.5-23 \mathrm{~kg} / \mathrm{m}^{2}, 23-27.5 \mathrm{~kg} / \mathrm{m}^{2}$, and $\geq 27.5 \mathrm{~kg} / \mathrm{m}^{2}$. Gravidity and parity were categorized as none, once or more pregnancies/births. History of miscarriages was classified into three categories: none, once, twice and more times, and history of induced abortion and history of preterm labor was categorized as none and once or more times.

Gestational hypertension was defined as having high blood pressure after 20 weeks according to the International Society for the Study of Hypertension in Pregnancy guidelines [20]. Chronic hypertension before 20 weeks of gestation was not an outcome of interest in this study. Gestational diabetes mellitus (GDM) was diagnosed by oral glucose tolerance test (OGTT) conducted at 24-28th week of gestation, with fasting plasma glucose $>5.6 \mathrm{mmol} / \mathrm{l}$ or with post- $75 \mathrm{~g}$ glucose load glucose level of $>8.8 \mathrm{mmol} / \mathrm{l}$ in 60th $\mathrm{min}$ or $>7.8 \mathrm{mmol} / \mathrm{l}$ in 120th min [21]. Anemia was defined as hemoglobin < $12.0 \mathrm{~g} / \mathrm{dL}$ [22]. Polyhydramnios and oligohydramnios were examined using ultrasound, and was defined as the 4-quadrant amniotic fluid index (AFI) $>24 \mathrm{~cm}$ or $\leq 5 \mathrm{~cm}$, respectively. Threatened abortion was defined as a small amount of vaginal bleeding, followed by paroxysmal lower abdominal pain or low back pain before the 28th week of pregnancy. The pelvic examination was not open, the membrane was intact, no pregnancy was discharged, and the size of the uterus was consistent with the gestational age. Preterm labor was defined as birth occurs before the start of the 37th week of pregnancy. Low birth weight is defined as the birth weight of an infant of $2499 \mathrm{~g}$ or less.

\section{Statistical analysis}

The demographic and pre-pregnancy characteristics of study participants were compared among four maternal age groups. Significant levels were compared using Chisquare tests, and all the tests were two-tailed. Incidence of pregnancy complications and mode of delivery were compared by parity and age groups, and we used subjects age 20 to 29 years as the reference group considering the low incidence of pregnancy complications in lower age groups. Logistic regression was used to calculate the odds ratio (OR) and 95\% confidence interval (CI) for pregnancy complications. Univariate analyses were conducted on all socio-demographic and prepregnancy characteristics to select the variable for adjustment, and significant variables were included in the multivariable model. Cramer's V statistics were used to evaluate the correlation between variables included in the final model. We were not able to conduct logistic regression for placenta previa, infectious disease, and threatened abortion among nulliparas due to low incidence rate. In the multivariate analysis, income level and BMI were adjusted for gestational hypertension, preeclampsia/eclampsia, and threatened abortion; occupation was adjusted for GDM and premature rupture of membrane; income level was adjusted for anemia, polyhydramnios, oligohydramnios, placenta previa, and infectious disease; occupation and history of preterm labor was adjusted for preterm labor; education and BMI were adjusted for the mode of delivery and low birth weight. All analyses were conducted using $R$ version 3.5.2.

\section{Results}

Socio-demographic and pre-pregnancy characteristics

A total of 12,170 pregnant women were admitted to the hospital from June 2013 to December 2015. Among them, 10,475 pregnant women were recruited in the study (response rate $86.1 \%$ ), and 10,171 subjects with complete information were included in the final analysis (97.1\%) (Fig. 1).

Among the 10,171 subjects, the average age was $26.7 \pm$ 4.2 years. $3274(32.2 \%)$ subjects were $20-24$ years old, 4587 (45.1\%) subjects were 25-29 years old, 1637 (16.1\%) subjects were $30-34$ years old, and $572(5.6 \%)$ subjects were 35 years old and older (Table 1 ). The majority of subjects $(85.9 \%)$ lived in rural areas, and the median family annual income was 20,000 Chinese Yuan per capita (around 2880 USD). The majority of subjects did not complete high school education (83.7\%), and most of them were housewives (54.3\%), factory workers (23.5\%), and farmers (13.9\%). The pre-pregnancy BMI was normal for $61.4 \%$ of subjects, $18.0 \%$ of subjects were underweight, and $20.5 \%$ of subjects were overweight/obese. Overall, around half of the subjects had one or more births previously, and the proportions were much higher for women aged $30-35$ years $(79.0 \%)$ and women aged 35 years and above (88.6\%) than younger age groups. Also, around onethird of women aged 35 years and above had two or more times of miscarriages, while the proportion ranged from 6.3 to $19.5 \%$ in younger age groups. $3.1 \%$ of subjects had a history of induced abortion, and the proportion ranged from 1.7 to $5.9 \%$ in different age groups.

\section{Incidence rates of pregnancy complications by parity and maternal age groups}

The comparison of incidence rates for different pregnancy complications stratified by parity and age groups is shown in Table 2. Overall, the incidence rate of each complication during pregnancy ranged from 0.9 to $4.2 \%$, and the top three pregnancy complications observed included gestational hypertension (4.2\%), preeclampsia or eclampsia (3.5\%), and anemia (3.7\%). The incidence of pregnancy complications showed an increasing pattern 


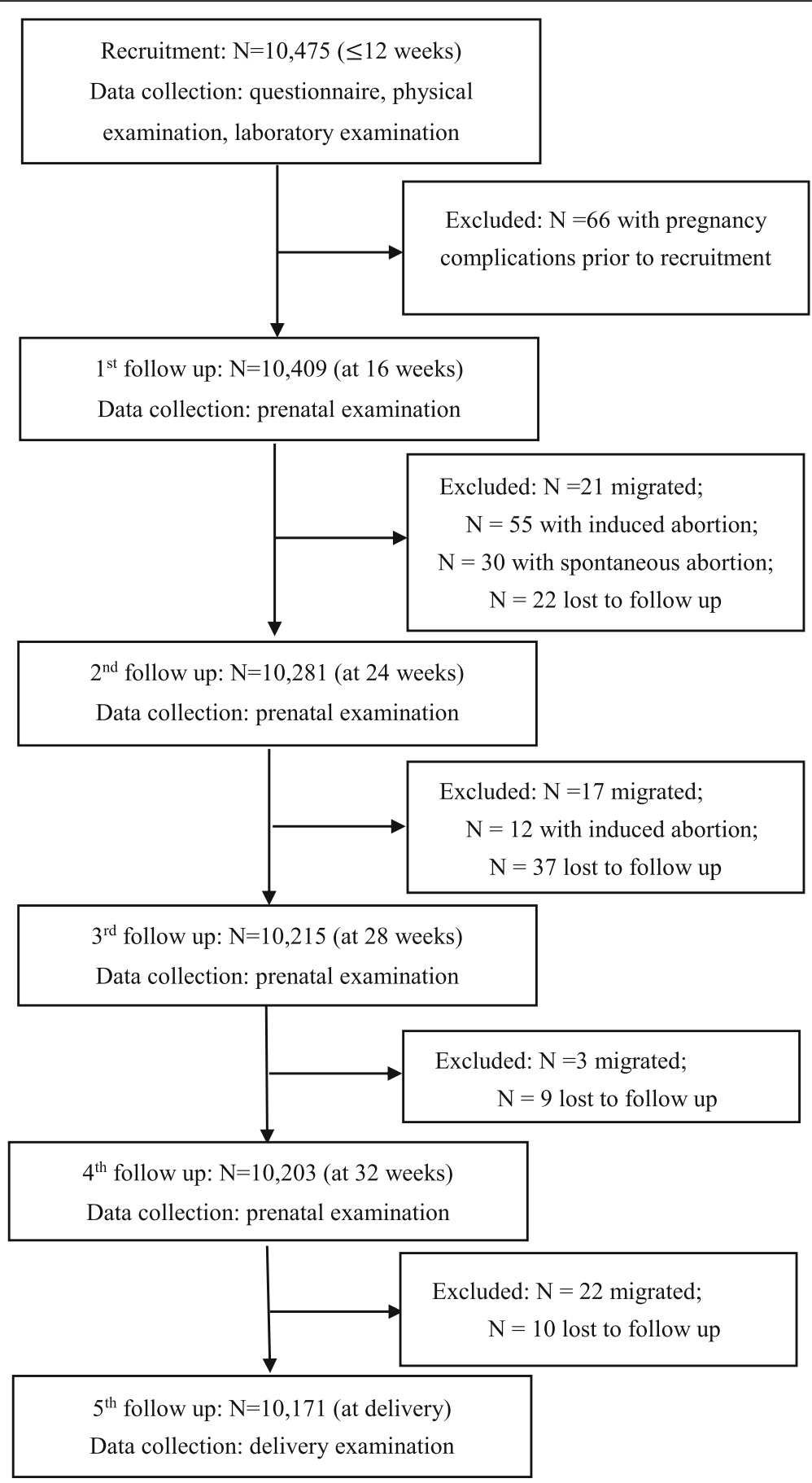

Fig. 1 Flow of inclusion to the current analysis

when stratified by age groups for gestational hypertension, preeclampsia, polyhydramnios, premature rupture of membrane among nulliparas, and this pattern was observed for GDM, anemia, polyhydramnios, oligohydramnios, placenta previa, premature rupture of membrane among multiparas. The incidence of preterm labor was $9.4 \%$, which ranged from 9.3 to $13.8 \%$ and 8.1 to $14.5 \%$ among different age groups in nulliparas and multiparas, respectively. The incidence of low birth weight was $2.8 \%$, and the incidence was higher in multiparas $(5.2 \%)$ than nulliparas $(0.7 \%)$. In terms of mode of delivery, around half of subjects aged 30 years old and above performed a cesarean delivery, while this proportion was around 30\% in the 20-29-year age group. 
Table 1 Socio-demographic and pre-pregnancy characteristics of study participants

\begin{tabular}{|c|c|c|c|c|c|c|}
\hline \multirow[t]{2}{*}{ Variables } & \multirow[t]{2}{*}{ Overall } & \multicolumn{4}{|c|}{ Maternal age groups (years) } & \multirow[t]{2}{*}{$p$} \\
\hline & & $20-24$ & $25-29$ & $30-34$ & $\geq 35$ & \\
\hline (n) & $(10,171)$ & (3274) & $(4587)$ & $(1637)$ & $(572)$ & \\
\hline Residential area $(n, \%)$ & & & & & & $<0.001$ \\
\hline Urban & $1437(14.1)$ & $396(12.1)$ & $742(16.2)$ & $222(13.6)$ & $68(11.9)$ & \\
\hline Rural & $8734(85.9)$ & $2878(87.9)$ & $3845(83.8)$ & $1415(86.4)$ & $504(88.1)$ & \\
\hline Family per capita annual income (Chinese Yuan, n, \%) & & & & & & 0.004 \\
\hline$\leq 10,000$ & $1647(16.2)$ & $550(16.8)$ & $684(14.9)$ & $267(16.3)$ & $124(21.7)$ & \\
\hline $10,001-20,000$ & $4147(40.8)$ & $1409(43.0)$ & $1805(39.4)$ & $660(40.3)$ & $223(39.0)$ & \\
\hline $20,001-30,000$ & $2871(28.2)$ & $922(28.2)$ & $1345(29.3)$ & $442(27.0)$ & $141(24.7)$ & \\
\hline$\geq 30,001$ & $1506(14.8)$ & $393(12.0)$ & $753(16.4)$ & $268(16.4)$ & $84(14.7)$ & \\
\hline Education level $(\mathrm{n}, \%)$ & & & & & & $<0.001$ \\
\hline Junior high school or lower & $8511(83.7)$ & $2822(86.2)$ & $3604(78.6)$ & $1456(88.9)$ & $532(93.0)$ & \\
\hline High school/college & $1660(16.3)$ & $452(13.8)$ & $983(21.4)$ & $181(11.1)$ & $40(7.0)$ & \\
\hline Occupation (n, \%) & & & & & & $<0.001$ \\
\hline Farmer & $1413(13.9)$ & $398(12.2)$ & $582(12.7)$ & $285(17.4)$ & $134(23.4)$ & \\
\hline Housewife & $5521(54.3)$ & $1768(54.0)$ & $2447(53.3)$ & $924(56.4)$ & $317(55.4)$ & \\
\hline Factory worker & $2395(23.5)$ & $819(25.0)$ & $1121(24.4)$ & $339(20.7)$ & $97(17.0)$ & \\
\hline Other & $842(8.3)$ & $289(8.8)$ & $437(9.5)$ & $89(5.4)$ & $24(4.2)$ & \\
\hline Pre-pregnancy BMI $\left(\mathrm{kg} / \mathrm{m}^{2}, \mathrm{n}, \%\right)$ & & & & & & $<0.001$ \\
\hline$<18.5$ & $1834(18.0)$ & $713(21.8)$ & $836(18.2)$ & $205(12.5)$ & $50(8.7)$ & \\
\hline $18.5-23$ & $6247(61.4)$ & $2028(61.9)$ & $2854(62.2)$ & $994(60.7)$ & $317(55.4)$ & \\
\hline $23-27.5$ & $1792(17.6)$ & $461(14.1)$ & $764(16.7)$ & $382(23.3)$ & $168(29.4)$ & \\
\hline$\geq 27.5$ & $298(2.9)$ & $72(2.2)$ & $133(2.9)$ & $56(3.4)$ & $37(6.5)$ & \\
\hline Gravidity (n, \%) & & & & & & $<0.001$ \\
\hline None & $3878(38.1)$ & $1861(56.8)$ & $1708(37.2)$ & $203(12.4)$ & $26(4.5)$ & \\
\hline Once or more pregnancies & $6293(61.9)$ & $1413(43.2)$ & $2879(62.8)$ & $1434(87.6)$ & $546(95.5)$ & \\
\hline Parity (n, \%) & & & & & & $<0.001$ \\
\hline None & $5354(52.6)$ & $2445(74.7)$ & $2406(52.5)$ & $344(21.0)$ & $65(11.4)$ & \\
\hline Once or more births & $4817(47.4)$ & $829(25.3)$ & $2181(47.5)$ & $1293(79.0)$ & 507 (88.6) & \\
\hline History of miscarriage (n, \%) & & & & & & $<0.001$ \\
\hline None & $6903(67.9)$ & $2506(76.5)$ & $3129(68.2)$ & 927 (56.6) & $256(44.8)$ & \\
\hline Once & $1988(19.5)$ & $563(17.2)$ & $891(19.4)$ & $390(23.8)$ & $130(22.7)$ & \\
\hline Twice or more times & $1280(12.6)$ & $205(6.3)$ & $567(12.4)$ & $320(19.5)$ & $186(32.5)$ & \\
\hline History of induced abortion (n, \%) & & & & & & $<0.001$ \\
\hline None & $9854(96.9)$ & $3218(98.3)$ & $4451(97.0)$ & $1546(94.4)$ & $538(94.1)$ & \\
\hline Once or more times & $317(3.1)$ & $56(1.7)$ & $136(3.0)$ & $91(5.6)$ & $34(5.9)$ & \\
\hline History of preterm labor (n, \%) & & & & & & 0.007 \\
\hline None & $10,110(99.4)$ & $3262(99.6)$ & $4562(99.5)$ & $1620(99.0)$ & $565(98.8)$ & \\
\hline Once or more times & $61(0.6)$ & $12(0.4)$ & $25(0.5)$ & $17(1.0)$ & $7(1.2)$ & \\
\hline
\end{tabular}

ORs for pregnancy complications in different maternal age groups by parity

Adjusted ORs for pregnancy complications calculated using logistic regression models are shown in Table 3. The risks for gestational hypertension (OR 8.44,
95\%CI 4.18-15.58) and preeclampsia/eclampsia (OR 9.92, 95\%CI 4.87-18.78) were significantly higher for women with AMA above among nulliparas compared with women aged 20-29years, while this association was not observed among multiparas. Among 
Table 2 Incidences of pregnancy complications by parity and maternal age groups

\begin{tabular}{|c|c|c|c|c|c|c|c|c|c|}
\hline \multirow[t]{2}{*}{ Variables } & \multirow[t]{2}{*}{ Overall } & \multicolumn{4}{|l|}{ Nulliparas } & \multicolumn{4}{|l|}{ Multiparas } \\
\hline & & $20-29 y^{a}$ & $30-34 y$ & $\geq 35 y$ & $p$ & $20-29 y$ & $30-34 y$ & $\geq 35 y$ & $p$ \\
\hline (n) & $(10,171)$ & $(4851)$ & (344) & (65) & & (3010) & (1293) & $(507)$ & \\
\hline Gestational hypertension (n, \%) & $430(4.2)$ & $126(2.6)$ & $34(9.9)$ & $12(18.5)$ & $<0.001$ & $125(4.2)$ & $109(8.4)$ & $20(3.9)$ & $<0.001$ \\
\hline Preeclampsia/eclampsia (n, \%) & $352(3.5)$ & $106(2.2)$ & $167(4.9)$ & $12(18.5)$ & $<0.001$ & $114(3.8)$ & $87(6.7)$ & $16(3.2)$ & $<0.001$ \\
\hline Gestational diabetes mellitus (GDM, n, \%) & $145(1.4)$ & $63(1.3)$ & $10(2.9)$ & $1(1.5)$ & 0.092 & $31(1.0)$ & $23(1.8)$ & $17(3.4)$ & $<0.001$ \\
\hline Anemia (n, \%) & $380(3.7)$ & $151(3.1)$ & $6(1.7)$ & $6(9.2)$ & 0.006 & $119(4.0)$ & $59(4.6)$ & $37(7.3)$ & 0.004 \\
\hline Polyhydramnios (n, \%) & $89(0.9)$ & $32(0.7)$ & $4(1.2)$ & $3(4.6)$ & 0.001 & $21(0.7)$ & $17(1.3)$ & $12(2.4)$ & 0.001 \\
\hline Oligohydramnios (n, \%) & $101(1.0)$ & $25(0.5)$ & $13(3.8)$ & $1(1.5)$ & $<0.001$ & $36(1.2)$ & $17(1.3)$ & $8(1.6)$ & 0.462 \\
\hline Placenta previa (n, \%) & $146(1.4)$ & $33(0.7)$ & $10(2.9)$ & $0(0.0)$ & $<0.001$ & $52(1.7)$ & $37(2.9)$ & $14(2.8)$ & 0.086 \\
\hline Premature rupture of membrane $(n, \%)$ & $90(0.9)$ & $43(0.9)$ & $7(2.0)$ & $4(6.2)$ & $<0.001$ & $11(0.4)$ & $14(1.1)$ & $10(2.0)$ & $<0.001$ \\
\hline Infectious disease (n, \%) & $158(1.6)$ & $29(0.6)$ & $3(0.9)$ & $0(0.0)$ & $<0.001$ & $75(2.5)$ & $36(2.8)$ & $14(2.8)$ & $<0.001$ \\
\hline Threatened abortion (n, \%) & $192(1.9)$ & $59(1.2)$ & $0(0.0)$ & $0(0.0)$ & 0.154 & $76(2.5)$ & $48(3.7)$ & $9(1.8)$ & $<0.001$ \\
\hline Preterm labor (n, \%) & $950(9.4)$ & $450(9.3)$ & $38(11.1)$ & $9(13.8)$ & 0.37 & $241(8.1)$ & $130(10.1)$ & $73(14.5)$ & $<0.001$ \\
\hline Low birth weight (n, \%) & $289(2.8)$ & $37(0.8)$ & $1(0.3)$ & $1(1.5)$ & 0.004 & $178(5.9)$ & $45(3.5)$ & $25(4.9)$ & 0.002 \\
\hline Mode of delivery (n, \%) & & & & & $<0.001$ & & & & $<0.001$ \\
\hline Vaginal birth & $6371(64.5)$ & $3401(72.0)$ & $189(56.9)$ & $94(62.3)$ & & $1852(63.1)$ & $592(47.4)$ & $243(49.6)$ & \\
\hline Caesarean & $3506(35.5)$ & $1321(28.0)$ & $143(43.1)$ & $40(63.5)$ & & $1081(36.9)$ & 657 (52.6) & $247(51.1)$ & \\
\hline
\end{tabular}

WWomen aged 20-24 years and 25-29 years were combined as one age group considering the low incidence of pregnancy complications in the two groups

multiparas, women with AMA were found to have increased risks for GDM (OR 3.29, 95\%CI 1.76-5.94), anemia (OR 1.85, 95\%CI 1.25-2.69), polyhydramnios (OR 3.29, 95\%CI 1.56-6.64), premature rupture of membrane (OR 5.14, 95\%CI 2.12-12.29), preterm labor (OR 1.89, 95\%CI 1.42-2.50), while similar associations were only observed for premature rupture of membrane (OR 6.84, 95\%CI 2.00-17.69) among nulliparas. Odds of performing cesarean delivery over virginal birth were significantly higher for women in older age groups as compared to the reference group both among nulliparas and multiparas.

Table 3 Multivariable adjusted odds ratios (ORs) for pregnancy complications by parity and maternal age groups

\begin{tabular}{|c|c|c|c|c|}
\hline \multirow[t]{2}{*}{ Variables } & \multicolumn{2}{|l|}{ Nulliparas } & \multicolumn{2}{|l|}{ Multiparas } \\
\hline & 30-34y (OR, 95\% Cl) & $\geq 35 y(\mathrm{OR}, 95 \% \mathrm{CI})$ & 30-34y (OR, 95\% Cl) & $\geq 35 y(\mathrm{OR}, 95 \% \mathrm{Cl})$ \\
\hline Gestational hypertension $^{a}$ & $4.17(2.76-6.14)^{*}$ & $8.44(4.18-15.85)^{*}$ & $2.2(1.68-2.88)^{*}$ & $0.97(0.58-1.54)$ \\
\hline Preeclampsia/eclampsia ${ }^{a}$ & $2.39(1.36-3.94)^{*}$ & $9.92(4.87-18.78)^{*}$ & $1.91(1.43-2.55)^{*}$ & $0.86(0.48-1.42)$ \\
\hline Gestational diabetesmellitus (GDM) ${ }^{b}$ & $2.22(1.06-4.18)$ & $1.08(0.06-5.04)$ & $1.74(1.00-2.99)$ & $3.29(1.76-5.94)^{*}$ \\
\hline Anemia $^{c}$ & $0.57(0.22-1.18)$ & $3.13(1.19-6.84)$ & $1.15(0.83-1.57)$ & $1.85(1.25-2.69)^{*}$ \\
\hline Polyhydramnios ${ }^{c}$ & $1.81(0.54-4.62)$ & $6.8(1.60-19.82)$ & $1.86(0.96-3.53)$ & $3.29(1.56-6.64)^{*}$ \\
\hline Oligohydramnios ${ }^{c}$ & $7.59(3.73-14.74)^{*}$ & $3.03(0.17-14.67)$ & $1.11(0.61-1.96)$ & $1.36(0.59-2.81)$ \\
\hline Placenta previa ${ }^{c}$ & - & - & $1.67(1.08-2.54)$ & $1.6(0.84-2.82)$ \\
\hline Premature rupture of membrane ${ }^{b}$ & $2.29(0.93-4.82)$ & $6.84(2.00-17.69)^{*}$ & $2.89(1.31-6.54)$ & $5.14(2.12-12.29)^{*}$ \\
\hline Infectious disease ${ }^{c}$ & - & - & $1.09(0.72-1.62)$ & $1.08(0.58-1.86)$ \\
\hline Threatened abortion $^{\mathrm{a}}$ & - & - & $1.45(0.99-2.09)$ & $0.66(0.31-1.27)$ \\
\hline Preterm labor $^{d}$ & $1.22(0.85-1.71)$ & $1.54(0.7-2.99)$ & $1.27(1.01-1.59)$ & $1.89(1.42-2.50)^{*}$ \\
\hline Low birth weight ${ }^{\mathrm{e}}$ & $0.38(0.02-1.77)$ & $1.86(0.1-8.93)$ & $0.55(0.39-0.77)^{*}$ & $0.78(0.49-1.17)$ \\
\hline Caesarean $^{\mathrm{e}}$ (ref. vaginal birth) & $1.88(1.5-2.36)^{*}$ & $4.06(2.43-6.93)^{*}$ & $1.84(1.61-2.11)^{*}$ & $1.65(1.36-2.01)^{*}$ \\
\hline
\end{tabular}

Women aged 20-29 years were used as the reference group. ${ }^{*}$ Indicate $p$-value was significant after Bonferroni correction

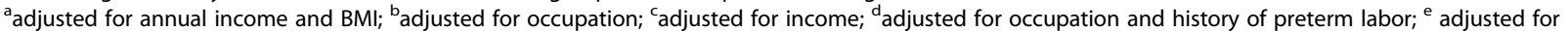
education and BMI 


\section{Discussion}

In this study, we found that women with AMA had a significantly higher incidence of pregnancy complications than women with younger age, and the increased risks of pregnancy complications varied by parity. More specifically, nulliparous women with AMA showed increased risks for gestational hypertension, preeclampsia/ eclampsia, and premature rupture of membrane, while multiparous women with AMA showed increased risks for GDM, anemia, polyhydramnios, premature rupture of membrane, and preterm labor. Cesarean delivery was also associated with older maternal age, where increased risks were found for women aged 30-35 years and 35 years and above in both nulliparas and multiparas compared to women aged 20-29 years.

We found that increased risks of gestational hypertension and preeclampsia/eclampsia for AMA were only observed in nulliparous women, not in multiparous women. Our finding is consistent with many studies that reported preeclampsia was more common in nulliparas [23], while inconsistent with some previous studies that found AMA was a risk factor for hypertensive disorders during pregnancy in both nulliparous and multiparous women [9]. On the other hand, one study also suggested that AMA was not associated with preeclampsia irrespective of parity [12]. Our findings may be explained by several factors. First, studies have suggested that hypertensive disease in nulliparous and multiparous pregnant women may involve different pathophysiology, especially in terms of immune maladaptation, though no conclusion has been made so far [23, 24]. Moreover, it's possible that the increased risk for the multiparous women with AMA was confounded by other risk factors, including history of hypertensive disorders in the first pregnancy, co-existence of other complications, and unhealthy lifestyle [25-27]. Future studies may be needed to examine the potential confounding factors, as well as the pathophysiology of pregnancy complications in women with different parity, to explore reasons behind this phenomenon.

Consistent with previous studies, the risks of GDM, anemia, polyhydramnios were increased in women with AMA compared to women aged 20-29 years in the multiparous group [7, 28]. GDM is a common pregnancy complication for women with AMA, and most scholars believe that the increased incidence may be due to change in blood volume, vascular endothelial injury, insulin receptor and insulin affinity decreased with aging [29-31]. Also, it has been reported that multiparity was associated with an increased risk of GDM [32], although the effects of increasing parity on insulin sensitivity or $\beta$ cell function were not detected [33]. Anemia during pregnancy is usually related to inadequate diets or not receiving prenatal iron and folate supplements [34].
Previous studies also reported that anemia was an independent risk factor for low birth weight and preterm delivery [35]. Considering the prevalence of underweight and low education level in this area, it's important to provide health education and support to prevent and control anemia especially for women with AMA in healthcare practice.

A national survey reported that the overall cesarean delivery rate in China had increased from $28.8 \%$ in 2008 to $34.9 \%$ in 2014 , with the rates increased linearly in rural and general urban areas but declined beyond baseline rates in super cities [36]. In this study, the overall cesarean delivery rate was $35.5 \%$, and AMA was found to be a risk factor for cesarean delivery, which is consistent with previous research [37]. With the change in child policy, the health care system should be prepared to cope with the increasing challenge of women with AMA and history of cesarean delivery.

This study has some limitations. First, subjects in this study were recruited at about 12 weeks of gestation based on the regulation of pregnant women in the health management registration system, thus we might underestimate the incidence rates of complications during early pregnancy. Also, it is possible that some subjects did not participate in all of the screening tests suggested by their gynecologist, especially for those with low education and income level, which may result in a lower incidence rate. However, the results of our study reflected the incidence of pregnancy complications in routine clinical practice. Second, only a few subjects in extreme age groups were included in the study, thus we were unable to conduct stratified analysis for subjects aged younger than 20 years old and subjects aged 40 years and above. Third, the results may be impacted by unmeasured confounding factors as we were not able to adjust for pre-pregnancy lifestyle and behaviors such as diet, smoking, and physical activity, although we have conducted adjusted models for sociodemographic factors and pre-pregnancy BMI.

\section{Conclusions}

To our knowledge, this is the first study to identify incidences of pregnancy complications in nulliparous and multiparous Chinese women with AMA using a community-based prospective cohort study. Our findings suggest that women with AMA should be regarded as high-risk groups for pregnancy complications in the practice of maternal health care and maternal care management. Also, different risks of pregnancy complications were observed for nulliparous and multiparous women with AMA. This study bears importance in early prevention of pregnancy complications in the practice of population-based pregnancy health care. 


\section{Supplementary information}

Supplementary information accompanies this paper at https://doi.org/10. 1186/s12884-020-03284-1.

\section{Additional file 1}

\section{Abbreviations}

AMA: Advanced maternal age; BMI: Body mass index; CNY: Chinese Yuan; GDM: Gestational diabetes mellitus; OGTT: Oral glucose tolerance test

\section{Acknowledgements}

The authors would like to thank all the researchers and staff from maternal and child health care centers in Liuyang City and the support from all the study participants.

\section{Authors' contributions}

JYL designed the original study. CLF, MYL, and JYL analyzed the data and drafted the manuscript. JQF, SJZ and FFZ involved as a research assistant for collecting data, monitoring and evaluation subject, and project administration. All authors provided critical input to the paper. All authors have read and approved the final manuscript.

\section{Funding}

The study was supported by the National Natural Science Foundation of China (grant number 81172680). This funding source had no role in the design of the study and collection, analysis, and interpretation of data and in writing the manuscript.

\section{Availability of data and materials}

The dataset generated and/or analyzed during the current study are not publicly available, but are available from the corresponding author on reasonable request.

\section{Ethics approval and consent to participate}

Ethical approval was obtained from the Ethics Committee of Xiangya School of Public Health, Central South University. Informed written consent was obtained from all participants.

\section{Consent for publication}

Not applicable.

\section{Competing interests}

The authors declare that they have no competing interests.

\section{Author details}

${ }^{1}$ Department of Women and Children Health, School of Public Health, Central South University, Changsha, Hunan Province, China. ${ }^{2}$ Hunan Provincial Key Laboratory of Clinical Epidemiology, Changsha, Hunan Province, China. ${ }^{3}$ Department of Gynecology, Maternal and Child Health Hospital of Hubei Province, Wuhan, Hubei Province, China. ${ }^{4}$ Department of Child Health Care, Hunan Provincial Maternal and Child Health Care Hospital, Changsha, Hunan Province, China. ${ }^{5}$ Department of Health, Liuyang Maternal and Child Health Care Hospital, Liuyang, Hunan Province, China.

\section{Received: 22 July 2020 Accepted: 25 September 2020}

Published online: 02 October 2020

\section{References}

1. Cheng P, Duan T. China's new two-child policy: maternity care in the new multiparous era. BJOG Int J Obstet Gynaecol. 2016;123(S3):7-9.

2. Li H, Zhou T, Jia C. The influence of the universal two-child policy on China's future population and ageing. J Popul Res. 2019;36(3):183-203.

3. Sauer MV. Reproduction at an advanced maternal age and maternal health. Fertil Steril. 2015;103(5):1136-43.

4. Matsuda Y, Kawamichi Y, Hayashi K, Shiozaki A, Satoh S, Saito S. Impact of maternal age on the incidence of obstetrical complications in Japan. J Obstet Gynaecol Res. 2011:37(10):1409-14

5. Kenny LC, Lavender T, McNamee R, O'Neill SM, Mills T, Khashan AS. Advanced maternal age and adverse pregnancy outcome: evidence from a large contemporary cohort. PLoS One. 2013;8(2):e56583.
6. Laopaiboon M, Lumbiganon P, Intarut N, Mori R, Ganchimeg T, Vogel J, et al. Advanced maternal age and pregnancy outcomes: a multicountry assessment. BJOG Int J Obstet Gynaecol. 2014;121(s1):49-56.

7. Jacobsson B, Ladfors L, Milsom I. Advanced maternal age and adverse perinatal outcome. Obstet Gynecol. 2004;104(4):727-33.

8. Bai J, Wong FWS, Bauman A, Mohsin M. Parity and pregnancy outcomes. Am J Obstet Gynecol. 2002;186(2):274-8.

9. Luke B, Brown MB. Elevated risks of pregnancy complications and adverse outcomes with increasing maternal age. Hum Reprod. 2007;22(5):1264-72.

10. Kanmaz AG, İnan AH, Beyan E, Ögür S, Budak A. Effect of advanced maternal age on pregnancy outcomes: a single-Centre data from a tertiary healthcare hospital. J Obstet Gynaecol. 2019;39(8):1104-11.

11. Danielsson KC, Borthen I, Gilhus NE, Morken NH. The effect of parity on risk of complications in pregnant women with epilepsy: a population-based cohort study. Acta Obstet Gynecol Scand. 2018;97(8):1006-14.

12. Wang Y, Tanbo T, Abyholm T, Henriksen T. The impact of advanced maternal age and parity on obstetric and perinatal outcomes in singleton gestations. Arch Gynecol Obstet. 2011;284(1):31-7.

13. Lin L, Wei Y, Zhu W, Wang C, Su R, Feng H, et al. Prevalence, risk factors and associated adverse pregnancy outcomes of anaemia in Chinese pregnant women: a multicentre retrospective study. BMC Pregnancy Childbirth. 2018;18(1):111.

14. Ye C, Ruan Y, Zou L, Li G, Li C, Chen Y, et al. The 2011 survey on hypertensive disorders of pregnancy (HDP) in China: prevalence, risk factors, complications, Pregnancy and Perinatal Outcomes. PloS one. 2014;9(6): e100180.

15. Liu X, Zhang W. Effect of maternal age on pregnancy: a retrospective cohort study. Chin Med J. 2014;127(12):2241-6

16. Shan D, Qiu PY, Wu YX, Chen Q, Li AL, Ramadoss S, et al. Pregnancy outcomes in women of advanced maternal age: a retrospective cohort study from China. Sci Rep. 2018;8(1):12239.

17. Clausen T, Øyen N, Henriksen T. Pregnancy complications by overweight and residential area. A prospective study of an urban Norwegian cohort. Acta Obstet Gynecol Scand. 2006;85(5):526-33.

18. Su Y, Xie X, Zhou Y, Lin H, Li Y, Feng N, et al. Association of induced abortion with hypertensive disorders of pregnancy risk among nulliparous women in China: a prospective cohort study. Sci Rep. 2020;10(1):5128.

19. WHO Expert Consultation. Appropriate body-mass index for Asian populations and its implications for policy and intervention strategies. Lancet (London, England). 2004;363(9403):157-63.

20. Brown MA, Lindheimer MD, de Swiet M, Van Assche A, Moutquin JM. The classification and diagnosis of the hypertensive disorders of pregnancy: statement from the International Society for the Study of Hypertension in Pregnancy (ISSHP). Hypertension Pregnancy. 2001;20(1):Ix-xiv.

21. Carpenter MW, Coustan DR. Criteria for screening tests for gestational diabetes. Am J Obstet Gynecol. 1982;144(7):768-73.

22. World Health Organization. Iron deficiency anemia. assessment, prevention, and control. A guide for programme managers. 2001:47-62.

23. Luo ZC, An N, Xu HR, Larante A, Audibert F, Fraser WD. The effects and mechanisms of primiparity on the risk of pre-eclampsia: a systematic review. Paediatr Perinat Epidemiol. 2007;21(Suppl 1):36-45

24. Gleicher N, Boler LR Jr, Norusis M, Del Granado A. Hypertensive diseases of pregnancy and parity. Am J Obstet Gynecol. 1986;154(5):1044-9.

25. Behrens I, Basit S, Melbye M, Lykke JA, Wohlfahrt J, Bundgaard H, et al. Risk of post-pregnancy hypertension in women with a history of hypertensive disorders of pregnancy: nationwide cohort study. BMJ. 2017:358:3078..

26. Jacobs DJ, Vreeburg SA, Dekker GA, Heard AR, Priest KR, Chan A. Risk factors for hypertension during pregnancy in South Australia. Aust N Z J Obstet Gynaecol. 2003;43(6):421-8.

27. Başer E, Seçkin KD, Erkılınç S, Karslı MF, Yeral IM, Kaymak O, et al. The impact of parity on perinatal outcomes in pregnancies complicated by advanced maternal age. J Turk Ger Gynecol Assoc. 2013;14(4):205-9.

28. Seoud MAF, Nassar AH, Usta IM, Melhem Z, Kazma A, Khalil AM. Impact of advanced maternal age on pregnancy outcome. Am J Perinatol. 2002; 19(01):001-8.

29. Gilbert WM, Nesbitt TS, Danielsen B. Childbearing beyond age 40: pregnancy outcome in 24,032 cases. Obstet Gynecol. 1999;93(1):9-14.

30. Retnakaran R, Hanley AJG, Raif N, Hirning CR, Connelly PW, Sermer M, et al. Adiponectin and beta cell dysfunction in gestational diabetes: pathophysiological implications. Diabetologia. 2005;48(5):993-1001.

31. Szoke E, Shrayyef MZ, Messing S, Woerle HJ, van Haeften TW, Meyer C, et al. Effect of aging on glucose homeostasis: accelerated deterioration of beta- 
cell function in individuals with impaired glucose tolerance. Diabetes Care. 2008;31(3):539-43.

32. Obukhov AG, Tian Y, Shen L, Wu J, Chen W, Yuan J, et al. Parity and the risk of diabetes mellitus among Chinese women: a cross-sectional evidence from the Tongji-Dongfeng cohort study. PLoS One. 2014;9(8):e104810.

33. Iversen DS, Støy J, Kampmann U, Voss TS, Madsen LR, Møller N, et al. Parity and type 2 diabetes mellitus: a study of insulin resistance and $\beta$-cell function in women with multiple pregnancies. BMJ Open Diabetes Res Care. 2016;4(1):e000237.

34. Sifakis S, Pharmakides G. Anemia in pregnancy. Ann N Y Acad Sci. 2006; 900(1):125-36.

35. Levy A, Fraser D, Katz M, Mazor M, Sheiner E. Maternal anemia during pregnancy is an independent risk factor for low birthweight and preterm delivery. Eur J Obstet Gynecol Reprod Biol. 2005;122(2):182-6.

36. Li HT, Luo S, Trasande L, Hellerstein S, Kang C, Li JX, et al. Geographic variations and temporal trends in cesarean delivery rates in China, 20082014. Jama. 2017;317(1):69-76.

37. Heffner L. Impact of labor induction, gestational age, and maternal age on cesarean delivery rates. Obstet Gynecol. 2003;102(2):287-93.

\section{Publisher's Note}

Springer Nature remains neutral with regard to jurisdictional claims in published maps and institutional affiliations.

Ready to submit your research? Choose BMC and benefit from:

- fast, convenient online submission

- thorough peer review by experienced researchers in your field

- rapid publication on acceptance

- support for research data, including large and complex data types

- gold Open Access which fosters wider collaboration and increased citations

- maximum visibility for your research: over $100 \mathrm{M}$ website views per year

At BMC, research is always in progress.

Learn more biomedcentral.com/submissions 